Article

\title{
Exploring the Use of Unprocessed Waste Chicken Eggshells for UV-Protective Applications
}

\author{
Daphne Fecheyr-Lippens ${ }^{1, *}$, Asritha Nallapaneni ${ }^{1,2}$ and Matthew D. Shawkey ${ }^{1,3}$ \\ 1 Department of Biology, the University of Akron, Akron, OH 44325, USA; na57@zips.uakron.edu (A.N.); \\ matthew.shawkey@ugent.be (M.D.S.) \\ 2 Department of Polymer Engineering, Polymer Engineering Academic Center, the University of Akron, \\ Akron, $\mathrm{OH} 44325$, USA \\ 3 Department of Biology, Evolution and Optics of Nanostructures Group, University of Ghent, \\ 9000 Ghent, Belgium \\ * Correspondence: daphne@fecheyr.be; Tel.: +32-486-36-18-12
}

Academic Editor: Vincenzo Torretta

Received: 13 December 2016; Accepted: 4 February 2017; Published: 9 February 2017

\begin{abstract}
Photodegradation causes a steady loss of the useful physical, mechanical and optical properties of materials, necessitating their replacement over time. Because UV (Ultraviolet) light is most harmful in this regard, many materials now contain UV-protective additives. However, these additives are not always effective and durable, can be expensive, and their natural extraction or synthetic production can be harmful to the environment. Here, we investigated the use of unprocessed chicken eggshells in providing UV protection to two commonly used synthetic polymers: polystyrene and nylon. We show that unprocessed chicken eggshells provide a durable and effective UV protection. Our data sets the stage for future research to find a practical way to use the large amounts of unprocessed chicken eggshell waste as novel, economically appealing and environmentally friendly UV-protective additives.
\end{abstract}

Keywords: photodegradation; waste management; chicken eggshell; environmentally friendly; ultra-violet protection

\section{Introduction}

Although sunlight is essential for life, it also has harmful effects. Most incident solar radiation that reaches Earth's surface is infrared (43\%) and visible light $(53 \%)$, and only a small portion is ultraviolet (UV; 4\%) [1]. However, the UV portion is most harmful due to its shorter wavelengths and higher energies [2]. The incident terrestrial solar UV consists of light with wavelengths between 290 and $400 \mathrm{~nm}$ because the stratospheric ozone absorbs UV-C (100-280 nm) and some UV-B (280-315 nm) [3]. UV light has deleterious effects on many materials, including synthetic polymers and naturally-occurring biopolymers such as skin, hair, and wood [4]. These materials absorb UV, triggering photolytic and photo-oxidative reactions, resulting in photodegradation and therefore a steady loss of useful physical, mechanical, and optical properties.

Substantial efforts have gone into reduction of photodamage and improvement of durability of photodegradable materials upon exposure to UV light using both organic and inorganic additives [4]. Organic additives generally absorb UV and are considered sacrificial components that only provide temporary protection. They usually require the addition of hindered amine light stabilizers (HALS) that react with free radicals formed by UV absorption and interfere with photo-oxidation reactions [5]. Inorganic additives are usually semiconductor oxides like $\mathrm{TiO}_{2}, \mathrm{ZnO}, \mathrm{SiO}_{2}$, and $\mathrm{Al}_{2} \mathrm{O}_{3}$, and whether they protect materials by reflecting or absorbing UV is unclear [6]. The most common inorganic additive is titanium dioxide $\left(\mathrm{TiO}_{2}\right)$, with a global consumption of more than 4 million tons in 2005 [7] of which 
about $60 \%$ is used as whitening and UV-protective additives in coatings [8]. The high refractive indices of rutile and anatase (the most common forms of $\mathrm{TiO}_{2}: 2.70$ and 2.55, respectively) enable them to efficiently scatter light when formed into particles of the appropriate size $(\sim 200 \mathrm{~nm})$ [9] and to absorb light regardless of particle size [6]. These optical properties make $\mathrm{TiO}_{2}$ an excellent UV-protectant. However, pigment chalking of paints and coatings containing $\mathrm{TiO}_{2}$ occurs under UV exposure [9]. Moreover, the natural extraction and synthetic production of $\mathrm{TiO}_{2}$ is environmentally harmful, quickly depletes finite resources, and is energy-intensive and costly [10]. $\mathrm{TiO}_{2}$ is also potentially carcinogenic to animals [11]. Thus, alternatives to $\mathrm{TiO}_{2}$ are needed for both environmental and economic reasons.

Here, we investigated the avian eggshell's potential as a UV-protectant. In a previous study, we found that white-colored chicken eggshells (Gallus gallus) reflect large amounts of UV light [12]. Moreover, chicken eggshell waste from manufacturing plants and food processing is currently generated at enormous amounts of several tons per day [13]. Most eggshell waste is discarded because further processing is too expensive and cumbersome, and unprocessed (i.e., still having the calcium carbonate $\left(\mathrm{CaCO}_{3}\right)$ eggshell and protein-rich membrane together) eggshells are considered useless [14]. Sending unprocessed eggshell waste to landfill is associated with a cost of more than $\$ 40$ a ton depending on the location of the landfill [15]. The main objective of our study is to find an environmentally and economically appealing use of waste chicken eggshells by turning them into valuable UV-additives, which can be used to protect against photodegradation.

\section{Materials and Methods}

We examined if chicken eggshells protect synthetic polymers (polystyrene and nylon) from UV degradation and compared their effectiveness with that of a commonly used UV-protective additive, which we identified as $\mathrm{TiO}_{2}$. We exposed the two polymers (covered by eggshells) to UV light for $800 \mathrm{~h}$ in a controlled UV-aging chamber. We then used scanning electron microscopy, spectrophotometry, and Fourier-transform infrared spectroscopy to determine if the polymers showed signs of UV degradation. We further took a first step to determine if eggshells in a more practical form (i.e., ground into a powder) would also provide protection against photodegradation by measuring the transmittance of UV light.

\subsection{Samples for the UV Aging Experiments}

\subsubsection{Polymers}

We analyzed photodegradation of two different synthetic polymers: polyamide 11 (PA-11, or nylon) and polystyrene (PS). We chose PS because it is a common UV weathering reference material that changes color (becomes yellow) quickly with UV exposure [16], and nylon because it is a common thermoplastic used for many industrial applications and has better sunlight resistance [17].

Styrene sheets (purchased from Plastics 2000, Modesto, CA, USA) were $1 \mathrm{~mm}$ thick, and $30 \times 30 \mathrm{~cm}$ in size. Two types of nylon were extruded from polymer pellets (only polymer: RILSAN BESNO; and polymer + UV-protective additives: RILSAN BESNO TL), into strips of $0.8 \mathrm{~mm}$ thick and $2.5 \mathrm{~cm}$ wide. The manufacturer of RILSAN BESNO TL did not specify the chemical identity of the UV-protective additives. The three different polymer specimens were cut into pieces of $2.5 \times 7 \mathrm{~cm}$.

\subsubsection{Eggshells}

We sourced white and brown unincubated and non-pasteurized chicken eggs (Gallus gallus domesticus) from a commercial farm in Akron, OH, USA. The egg white and yolk were carefully removed and the eggshells were washed with deionized (DI) water and 100\% ethanol (Sigma, St. Louis, $\mathrm{MO}, \mathrm{USA}$ ). The eggshells were fragmented into $1 \mathrm{~cm}^{2}$ pieces using soft pressure and stored in the dark at room temperature. 


\subsubsection{Quartz Coverslip}

As the control, we covered the polymers with UV-transparent $25 \times 25 \times 0.2 \mathrm{~mm}$ quartz coverslips (EMS, Hatfield, PA, USA). We stacked two coverslips to achieve a thickness similar to the chicken eggshells $(\sim 450 \mu \mathrm{m})$. This control allowed us to determine if the UV protectiveness of the eggshells is the result of its chemical and/or physical properties rather than the effect of simply representing a physical barrier thick enough to block or filter the passage of light. We used quartz as it does not interfere with UV wavelengths [18] and the exclusive effect of the material thickness can be tested.

\subsection{UV Aging Chamber}

To assess the effect of UV exposure on photo-degradation of the polymers, we mounted the specimens in a QUV Accelerated Weathering Tester (Q-Lab, Westlake, OH, USA). Accelerated weathering testers are commonly used as they provide results more quickly (i.e., UV degradation is accelerated compared to natural conditions) and are more economically viable than extensive outdoor exposure experiments [19]. However, the data are relative because it is theoretically impossible to have a single conversion number to calculate the years of outdoor hours from the UV-exposed hours in the UV chamber [20]. The experiments were performed with fluorescent UV-340 lamps because they simulate sunlight in the region of the spectrum that causes most polymer damage (295-365 nm) [19]. The UVA-340 lamps were operated at $0.85 \mathrm{~W} / \mathrm{m}^{2} / \mathrm{nm}$. A single exposure temperature of $45^{\circ} \mathrm{C}$ was chosen according to SAE (Society of Automotive Engineers) Standard J844.

\subsection{Specimen Installation}

The polymer strips were cut into pieces of $2.5 \times 7 \mathrm{~cm}$ and wrapped in aluminum foil to protect them from UV degradation. Pieces of $1 \mathrm{~cm}^{2}$ were cut in the aluminum foil to expose the polymer, and were then covered either by a piece of eggshell or by the quartz coverslips as control (Figure 1). The specimens were mounted on standard specimen holders (Q-Lab, Westlake, OH, USA).

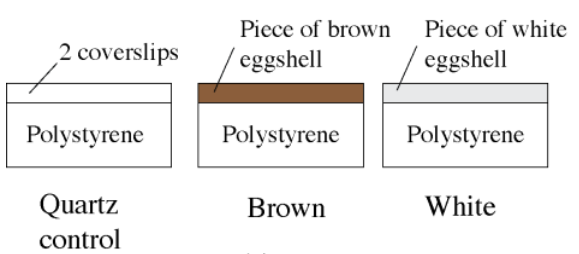

(a)

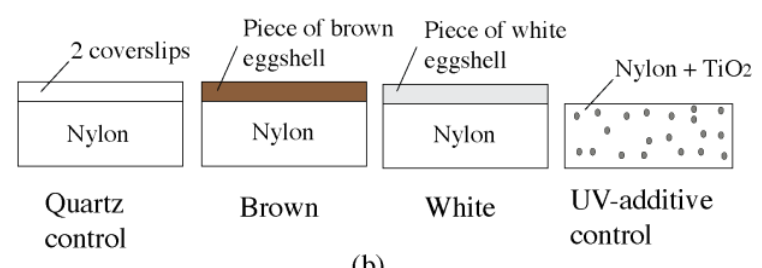

(b)

Figure 1. Schematic showing the UV aging experimental setup to test the UV protectiveness of white and brown eggshells (replicates $n=3)(\mathbf{a})$; and compared to a commonly used UV-protective additive $(n=6)(\mathbf{b})$.

\subsection{Experimental Setup}

To test for differences in UV protectiveness between the white and brown colored eggshells, we covered polystyrene with a piece of eggshell of each color (Figure 1a). In the second replicate, we compared the UV protectiveness of eggshells with that of a commonly used UV-protective additive (Figure 1b). Here, we compared specimens of nylon (Rilsan ${ }^{\circledR}$ BESNO, Arkema, Colombes, France) covered with eggshells to a specimen of nylon that includes UV-protective additives (Rilsan ${ }^{\circledR}$ BESNO $\mathrm{TL}$, Arkema, Colombes, France; which we identified as $\mathrm{TiO}_{2}$ ).

\subsection{Temperature Measurement}

To control for any possible thermal degradation effects, we measured the temperature beneath one brown- and one white-colored eggshell and one set of quartz coverslips. We mounted small temperature TK-4023 monitors (Gemini Data Loggers Ltd., Chichester, UK) beneath the samples 
and the Tinytag Talk Thermistor Probes (Gemini Data Loggers Ltd., Chichester, UK) registered the temperature each hour during the entire $800 \mathrm{~h}$ of continuous UV exposure.

\subsection{Fourier-Transform Infrared Spectroscopy (FTIR)}

We used FTIR to measure the amount of photodegradation. FTIR spectra were collected on a Nicolet 6700 FTIR spectrometer (Thermo Scientific, Waltham, MA, USA), and analyzed using the software Essential FTIR. The spectra were produced from 32 scans at a $4 \mathrm{~cm}^{-1}$ resolution. We quantified photo-oxidation by calculating the area underneath the peak in the $1750-1600 \mathrm{~cm}^{-1}$ region [21], which corresponds to the carbonyl group.

\subsection{Statistical Analysis}

We performed a one-way ANOVA and Tukey multiple comparison tests $(\alpha=0.05)$ to compare the different specimens with respect to the amount of UV degradation to the material underneath. All statistical tests were implemented in R v.3.0.1 (The R Foundation, Vienna, Austria) [22].

\subsection{UV Transmittance through Eggshell and $\mathrm{TiO}_{2}$ Particles Suspension Films}

We purchased white and brown chicken eggs from a grocery store. The egg white and yolk were carefully removed and were washed with DI water and 100\% ethanol. White and brown egg shells were separately ground using a pestle and mortar into fine particles. Titanium dioxide $\left(\mathrm{TiO}_{2}\right)$ nanoparticles of a size less than $100 \mathrm{~nm}$ were purchased from Sigma Aldrich (St. Louis, MO, USA). We made three suspensions using $50 \mathrm{mg}$ eggshell particles (white and brown) and $\mathrm{TiO}_{2}$ particles in $500 \mu \mathrm{L}$ DI water resulting in $100 \mathrm{mg} / \mathrm{mL}$ suspensions. However, the particles settled down and did not form uniform suspensions. Hence, the suspensions were mixed thoroughly before casting films. We made films by drop casting $100 \mu \mathrm{L}$ of the suspension on a glass slide and letting them dry overnight.

\subsection{Scanning Electron Microscopy (SEM)}

We used SEM to examine physical damage of the polymers caused by UV exposure. We also used SEM to determine the morphology of the films of the eggshell and $\mathrm{TiO}_{2}$ particles. We mounted the samples onto aluminum stubs using double-sided tape, which we sputter-coated with gold/palladium for $3 \mathrm{~min}$. SEM (JSM7401F, JEOL, Tokyo, Japan) images were taken at a working distance around $8 \mathrm{~mm}$ with an accelerating voltage of $5 \mathrm{kV}$.

\subsection{UV-Vis Spectrophotometry}

We used spectrophotometry to test for color changes of the polymers indicating photodegradation. We measured diffuse reflectance of the polymer samples between 300 and $700 \mathrm{~nm}$. We used an integrating sphere (AvaSphere-50-REFL, Avantes Inc., Broomfield, CO, USA) with a black gloss trap to exclude specular reflectance, an AvaSpec-2048 spectrometer, and an AvaLight-XE pulsed xenon light source (Avantes Inc., Broomfield, CO, USA). All reflectance measurements were taken relative to a diffuse white standard (WS-2, Avantes Inc., Broomfield, CO, USA).

We also used spectrophotometry to measure the transmittance of UV light through the eggshell and $\mathrm{TiO}_{2}$ films. The spectrophotometer was equipped with two fibres that rotate independently from one another. One fibre was connected to a light source (AvaLight-XE pulsed xenon light) and the other fibre to a spectrophotometer (AvaSpec-2048, Avantes Inc., Broomfield, CO, USA). Transmittance measurements were normalized using a glass slide as standard. Light was incident normal to the suspended film. 


\section{Results and Discussion}

\subsection{UV Aging of Two Synthetic Polymers}

\subsubsection{Temperature Measurement}

Although we set the temperature of the UV aging chamber to $45^{\circ} \mathrm{C}$, we measured the temperature underneath the eggshells and quartz coverslips (Figure S1) to investigate if the eggshells affected the temperature underneath the surface. The highest temperature measured was $46^{\circ} \mathrm{C}$, and there was no noticeable difference in temperature between the eggshells and the quartz coverslips. Pigmentation of eggshells has been hypothesized to increase the temperature inside the eggs [23], but UV-radiation alone did not cause an increase in temperature beneath the eggshell surfaces (Figure S1). Thermal oxidative degradation of the polymers only occurs on temperatures above $120{ }^{\circ} \mathrm{C}[24]$, thus any degradation of the polymers detected is not due to thermal oxidative degradation and thus can be attributed to photo-oxidation caused by UV-radiation.

\subsubsection{Scanning Electron Microscopy}

Scanning electron microscopy (SEM) images showed that $800 \mathrm{~h}$ of UV exposure caused cracking of both synthetic polymers in the control specimens, but, when they were covered with eggshells, their physical integrity was maintained (Figure 2). The eggshells thus provided a protective covering to the polymers against the high energies of UV-radiation that caused physical damage in controls.
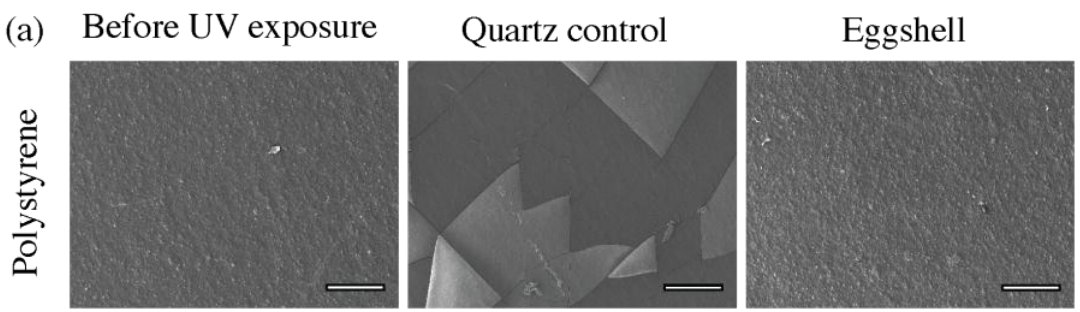

(b) Before UV exposure
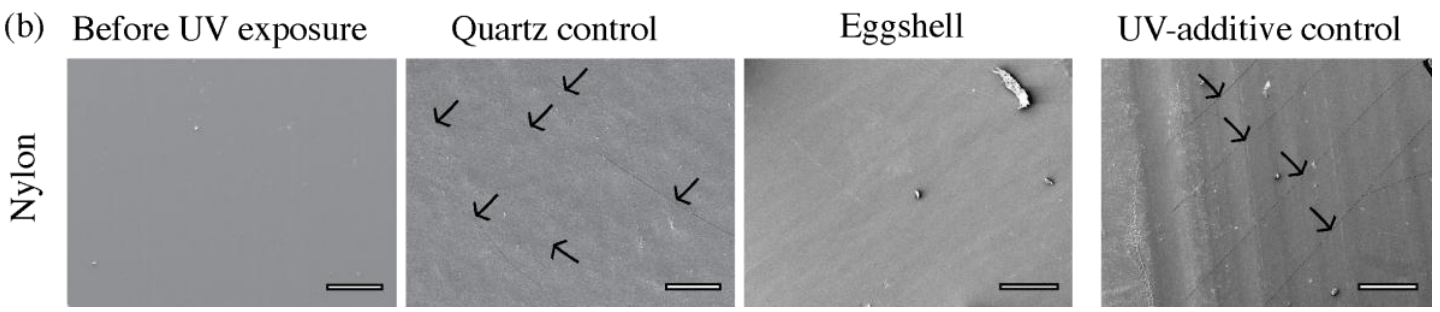

Figure 2. SEM images of polystyrene (a) and nylon (b) before and after UV exposure. Scale bars $=200 \mu \mathrm{m}$. Arrows highlight cracks formed in the polymer.

\subsubsection{Spectrophotometry}

We measured diffuse reflectance of the polymers before and after UV exposure to measure if it caused alteration of optical properties (Figure 3). Polystyrene showed yellowing after UV exposure, which was clearly visible to human eyes (Figure 3b) and detectable with spectrophotometry (Figure 3a). There was a clear difference in the degree of yellowing between the control specimen and the eggshell specimens. However, there was no distinguishable difference between the white and brown eggshells. UV exposure did not change the color of the nylon specimens (Figure S2). 


\section{(a)}

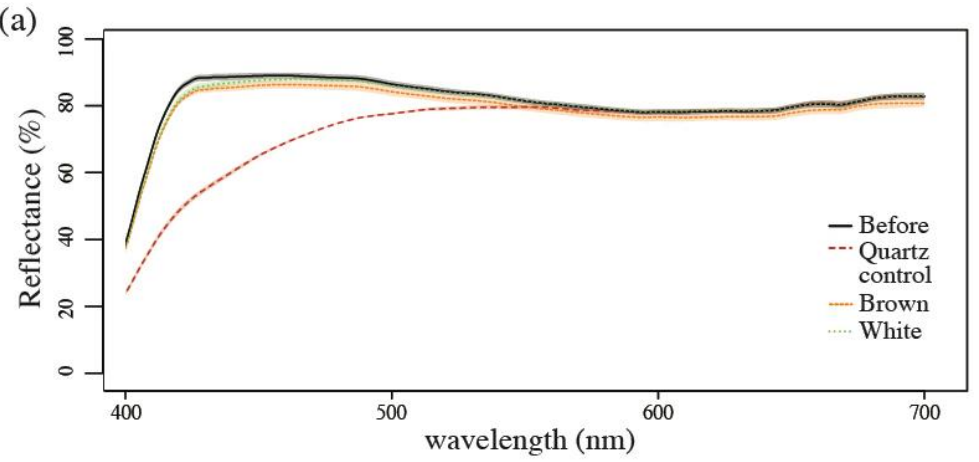

(b)

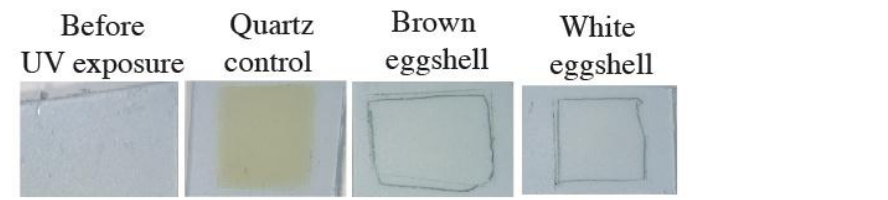

Figure 3. Diffuse reflectance spectra show changes in optical properties of polystyrene after UV exposure in the control but not when covered by eggshells (a); plotted lines are group mean spectra $(n=3)$ with shaded areas representing the standard error. The yellowing of polystyrene is visible to the human eye (b).

\subsubsection{Fourier-Transform Infrared Spectroscopy}

We used Fourier-Transform Infrared Spectroscopy (FTIR) to investigate if UV-radiation caused decomposition and formation of chemical bonds in the synthetic polymers (Figures 4 and 5). The FTIR spectra showed that UV degradation caused a significant increase of the peak in the $1750-1600 \mathrm{~cm}^{-1}$ region for both polymers compared to the controls (for full spectra, see Figures S3 and S4). This region corresponds to the carbonyl group and may increase due to photo-oxidation [21]. UV degradation was greater for polystyrene (Figure 4) than nylon (Figure 5a,b). Covering the polymers with eggshells provided a significantly greater protection against UV degradation than controls (Figures 4 and 5; for statistics, see Tables S1 and S2). Covering nylon with eggshells provided a significantly greater protection against UV degradation than the nylon with embedded UV-protective additives (brown eggshell vs. UV-protective additive $57.1 \%$ higher; white eggshell vs. UV-protective additive $43.5 \%$ higher UV protection; Figure 6). FTIR analysis showed that the sample with the UV-protective additive had an extra peak around $3700 \mathrm{~cm}^{-1}$, which corresponds to that of $\mathrm{TiO}_{2}$ [25]. Surprisingly, the $\mathrm{TiO}_{2}$ peak was no longer detected after $100 \mathrm{~h}$ of UV exposure (Figure $5 \mathrm{~d}$ ). A possible explanation is that the $\mathrm{TiO}_{2}$ particles are still present deeper in the polymer, but are not detected by FTIR, which is limited to detection of the surface [6]. Interestingly, nylon photo-oxidized at the highest rate for the first $100 \mathrm{~h}$, but the rapid photo-oxidation rate slowed down for the remainder of the treatment period (Figure 5, left inset). Zan et al. (2004) showed that $\mathrm{TiO}_{2}$ particles enhanced photo-oxidative degradation of polystyrene by generating reactive oxygen species under UV-illumination [26]. The hydroxyl radicals and active oxygen species formed attack the $\mathrm{C}-\mathrm{H}$ bond in the polymer chain to form the carbonyl group [26]. Chen et al. (2007) showed that the crystal structure also plays an important role as anatase $\mathrm{TiO}_{2}$ nanoparticles were intrinsically more photo-catalytically active than rutile $\mathrm{TiO}_{2}$ nanoparticles in photo-oxidative degradation of polyurethane [27]. A possible explanation for our results is that during the first $100 \mathrm{~h} \mathrm{TiO}{ }_{2}$ particles led to an increase of the efficiency of the photo-oxidative degradation of nylon, which slowed down after the loss of $\mathrm{TiO}_{2}$. 


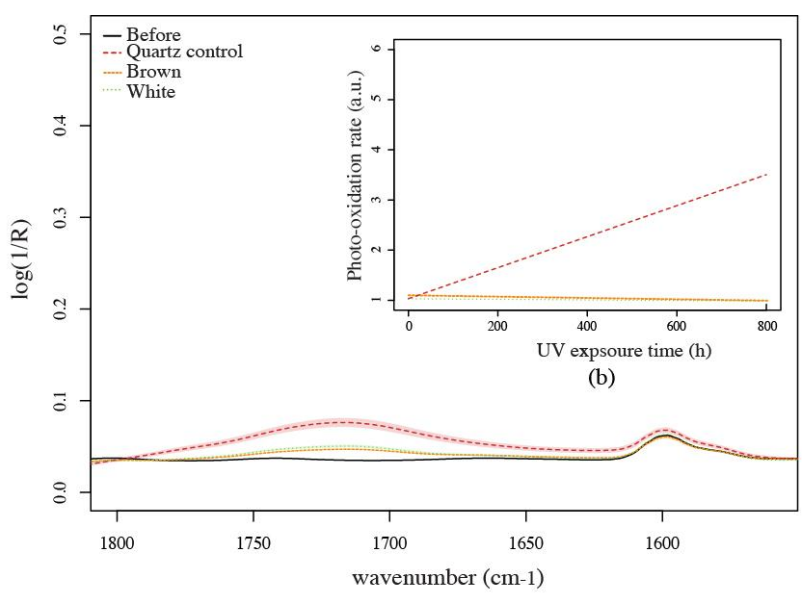

(a)

Figure 4. FTIR spectra of polystyrene before and after $800 \mathrm{~h}$ of UV exposure (a); the inset shows the degree of photo-oxidation (b), which is the calculated by integrating the area underneath the peak in the $1750-1600 \mathrm{~cm}^{-1}$ region. Plotted lines are group mean spectra $(n=3)$ with shaded areas representing the standard error.

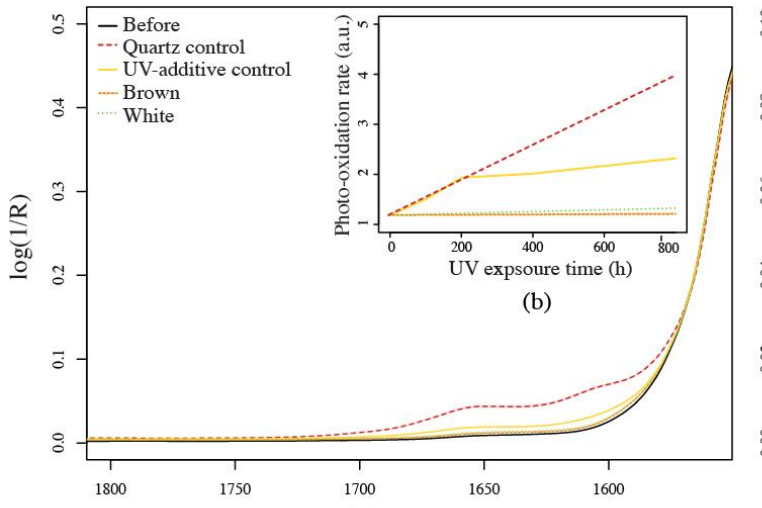

(a)

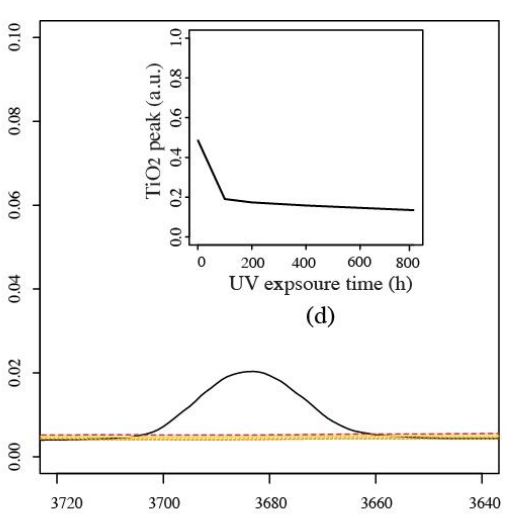

(c)

Figure 5. FTIR spectra of nylon before and after $800 \mathrm{~h}$ of UV exposure (a); the inset shows the degree of photo-oxidation (b), which is the calculated by integrating the area underneath the peak in the 1750-1600 $\mathrm{cm}^{-1}$ region. The FTIR spectra show that the sample with the UV-additive has an extra peak around $3700 \mathrm{~cm}^{-1}$ (c); which disappeared after $100 \mathrm{~h}$ of UV exposure (d). Plotted lines are group mean spectra $(n=6)$ with shaded areas representing the standard error.

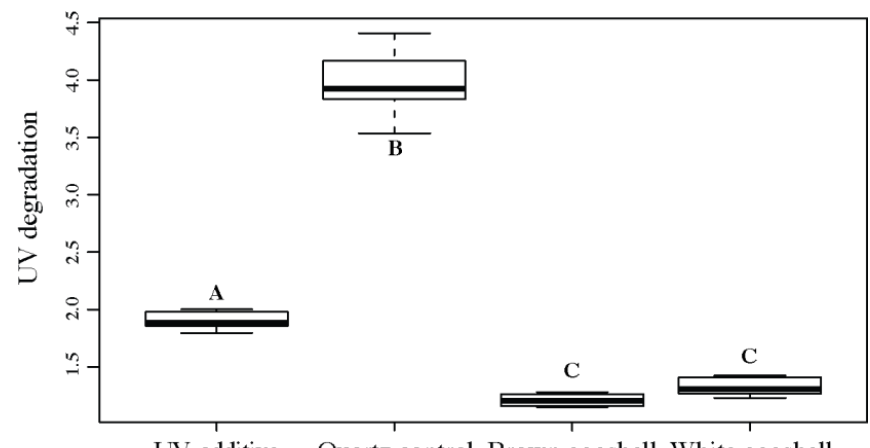

UV-additive Quartz control Brown eggshell White eggshell

Figure 6. Boxplots showing the degree of UV degradation of nylon after $800 \mathrm{~h}$ of UV exposure. Box $=25$ th and 75 th percentiles, with median shown as a thick line; bars are minimum and maximum values. Means with different letters (A, B, C) are significantly different (Tukey's HSD, $p<0.01, n=6$ ). 


\subsection{UV Transmittance through Eggshell and $\mathrm{TiO}_{2}$ Particle Suspension Films}

The suspension films of the eggshells show that the particles had irregular sizes and geometries (Figure S5), while the suspension film of $\mathrm{TiO}_{2}$ particles is more homogenous. Some particles of the ground eggshells were too large, making measurement of the size-range of the particles by Dynamic Light Scattering impossible. However, SEM images (Figure S5) showed that some particles were larger than 100 microns, an order of magnitude larger than the $\mathrm{TiO}_{2}$ particles, which are approximately $100 \mathrm{~nm}$. Nevertheless, we were able to make films of the eggshell particles and measure UV transmittance using a UV-Vis spectrophotometer (Figure 7). For all three films, the UV transmittance was low (under 10\%) and not significantly different. This promising result suggests that unprocessed waste chicken eggshell in a more useful format (i.e., ground into a powder) likely will provide UV protection, as UV-radiation does not pass through. However, we do not know why UV is not transmitted through the films (i.e., UV reflection, absorption or scattering), so further experiments should be performed to test the applicability of eggshell particles as UV-protective additives for industrial applications.

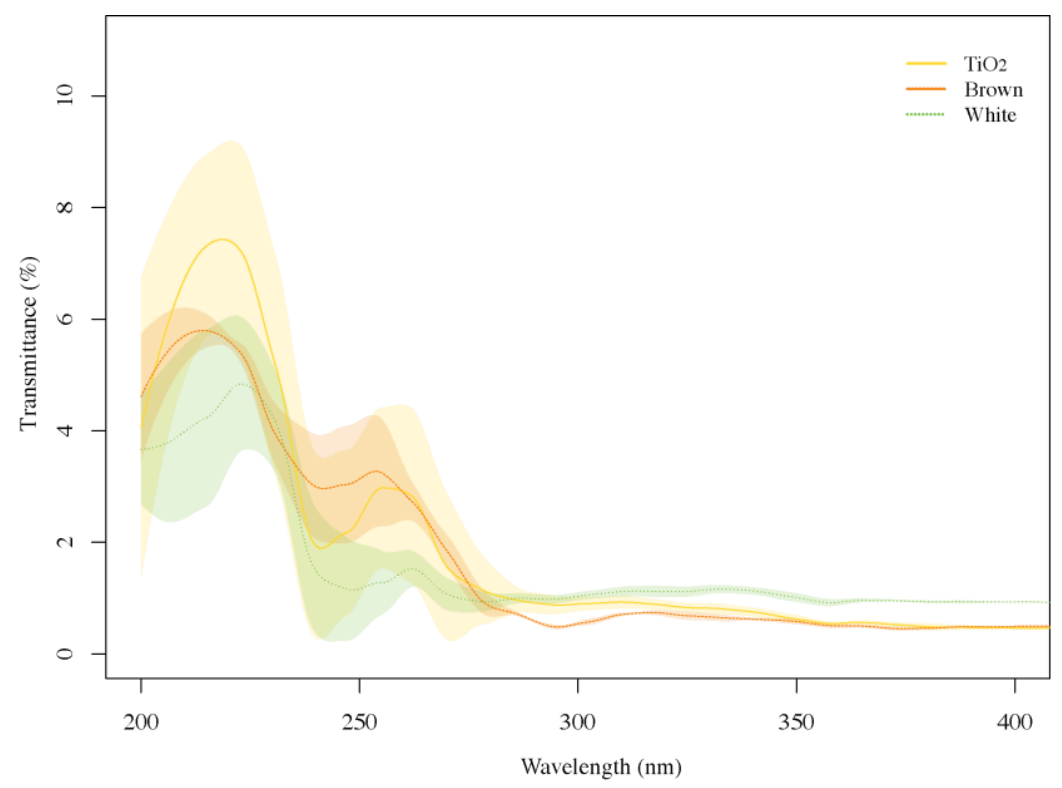

Figure 7. The suspension films of $\mathrm{TiO}_{2}$, white, and brown eggshell particles trap most of the UV light. The three films show comparable transmittance values that are well below $10 \%$. Plotted lines are group mean spectra $(n=3)$ with shaded areas representing the standard error.

\section{Conclusions}

Chicken eggshell waste is becoming an environmental concern due to its rapidly increasing amount and high costs to dispose it. In particular, unprocessed eggshells are considered a problem, as the protein-rich membrane attracts rats to landfills [28]. Moreover, the processing of eggshells is cumbersome and expensive, thus further increasing the likelihood that chicken eggshells will be classified as waste [29]. It is thus of increasing interest to find valuable applications for unprocessed eggshells. In our study, we showed promising results for the use of unprocessed eggshells in providing protection against photo-oxidative degradation of polymers. The placement of eggshell pieces provided effective and durable protection to nylon and polystyrene during $800 \mathrm{~h}$ of high UV-illumination. The nylon protected with eggshells showed slower photo-oxidative rates compared to nylon that was protected with embedded $\mathrm{TiO}_{2}$ particles. The UV protection was $57.1 \%$ higher for brown eggshell and $43.5 \%$ higher for white eggshells than that of nylon with $\mathrm{TiO}_{2}$ particles. Surprisingly, the photo-oxidative rate was high during the first $100 \mathrm{~h}$ of UV exposure for nylon with embedded $\mathrm{TiO}_{2}$ particles, but, after loss of $\mathrm{TiO}_{2}$, it slowed down. It is likely that the presence of $\mathrm{TiO}_{2}$ 
actually increased the efficiency of photodegradation due to the formation of active radicals rather than providing photoprotection.

It is unlikely that pieces of eggshells would be used in this form for practical applications. We took one step to determine if eggshells would also be useful in a more practical format. Our results showed that a thin film of grinded eggshell particles had the same capacity as a thin film of $\mathrm{TiO}_{2}$ particles to omit UV radiation to pass through. A next step will be to compare the UV-resistance of a nylon strip with embedded chicken eggshell particles with that of a nylon strip with embedded $\mathrm{TiO}_{2}$ particles.

Synthetic $\mathrm{CaCO}_{3}$ particles have been widely used as inorganic filler for many industrial applications, including construction, healthcare, polymer industry and coatings [30], but the use of chicken eggshells might provide significant differences. Although chicken eggshells are also predominantly made from $\mathrm{CaCO}_{3}$, they also contain organic component. Biominerals in many cases show superior properties to synthetic equivalents [31] and their nanostructural organization is often organized in hierarchical levels, making them distinct from traditional engineered composites [32]. For example, different or even new crystal faces that cannot be expressed in synthetic $\mathrm{CaCO}_{3}$ are preferred in biominerals, leading to stronger materials that are more resistant to fracturing [33]. Therefore, the use of waste chicken eggshells as organic-inorganic composites as an alternative to engineered composites can be attractive for various applications. Even more, chicken eggshells are being used as food additives and as a source of calcium in animal and human nutrition [29], thus providing evidence that is not harmful. Possible applications where eggshell particles could be used as UV-additives include synthetic polymers such as polystyrene and sunscreens. Polystyrene is widely used in building and packaging as expanded foam, but undergoes light-induced yellowing [34]. As previously noticed [26], and confirmed in our study, $\mathrm{TiO}_{2}$ particles can actually speed up its photo-oxidative degradation rather than providing photoprotection. Sunscreens often include $\mathrm{TiO}_{2}$ particles as inert light scatters and are supposed to provide improved protection in the UVA region [35]. However, it is shown that the presence of $\mathrm{TiO}_{2}$ can actually increase the loss of UV protection due to photodegradation of the organic fillers $[35,36]$. Thus, here the non-harmful eggshell particles might also provide a valuable alternative for $\mathrm{TiO}_{2}$ particles.

Supplementary Materials: The following are available online at www.mdpi.com/2071-1050/9/2/232/s1, Figure S1: Temperature measured underneath a white and a brown chicken eggshell, and the quartz coverslips; Figure S2: Diffuse reflectance spectra showing no changes of optical properties of nylon after $800 \mathrm{~h}$ UV exposure. Plotted lines are group mean spectra $(n=3)$ with shaded areas representing the standard error; Figure S3: Full FTIR spectra of polystyrene before and after $800 \mathrm{~h}$ of UV exposure. Plotted lines are group mean spectra $(n=3)$ with shaded areas representing the standard error; Figure S4: Full FTIR spectra of nylon before and after $800 \mathrm{~h}$ of UV exposure. Plotted lines are group mean spectra $(n=6)$ with shaded areas representing the standard error; Figure S5: Optical (a) and SEM (b) images of suspension films of $\mathrm{TiO}_{2}$ particles, brown eggshell particles and white eggshell particles. Scale bars of optical images are $500 \mu \mathrm{m}$ and SEM images are $100 \mu \mathrm{m}$; Table S1: One-way ANOVA and Tukey multiple comparison tests $(\alpha=0.05)$ for UV degradation of polystyrene $(n=3)$; Table S2: One-way ANOVA and Tukey multiple comparison tests $(\alpha=0.05)$ for UV degradation of nylon $(n=6)$.

Acknowledgments: This works is supported by Parker Hannifin and by a Human Frontiers Science Program grant (RGY-0083). We thank Jonathan Markley and Joseph Horinger for extruding the nylon strips, providing the UV chamber, and assisting with the FTIR measurements. We thank our colleagues of the Shawkey lab for comments on the manuscript and specifically Branislav Igic for helping with the statistics.

Author Contributions: Daphne Fecheyr-Lippens and Matthew D. Shawkey conceived and designed all experiments, Asritha Nallapaneni designed the UV transmittance experiment; Daphne Fecheyr-Lippens performed the UV aging experiments and Asritha Nallapaneni performed the UV transmittance experiment; Daphne Fecheyr-Lippens analyzed the data; Matthew D. Shawkey contributed materials and analysis tools; Daphne Fecheyr-Lippens wrote the paper.

Conflicts of Interest: The authors declare no conflict of interest. The founding sponsors had no role in the design of the study; however, Parker Hannifin provided the nylon strips and assisted in the collection of the FTIR analyses.

\section{References}

1. Brooks, E.R. Critical Color: The Use of Color in Nature for Energy Performance and Its Application to Building Skins. Ph.D. Thesis, University of Washington, Seattle, WA, USA, September 2012. 
2. Rabek, J.F. Polymer Photodegradation: Mechanisms and Experimental Methods; Springer Science \& Business Media: Berlin, Germany, 1995.

3. Madronich, S.; Flocke, S. Theoretical Estimation of Biologically Effective UV Radiation at the Earth's Surface. In Solar Ultraviolet Radiation; Zerefos, C.S., Bais, A.F., Eds.; NATO ASI Series; Springer: Berlin/Heidelberg, Germany, 1997; pp. 23-48.

4. Andrady, A.L.; Hamid, S.H.; Hu, X.; Torikai, A. Effects of increased solar ultraviolet radiation on materials. J. Photochem. Photobiol. B 1998, 46, 96-103. [CrossRef]

5. Berdahl, P.; Akbari, H.; Levinson, R.; Miller, W.A. Weathering of roofing materials-An overview. Constr. Build. Mater. 2008, 22, 423-433. [CrossRef]

6. Yang, H.; Zhu, S.; Pan, N. Studying the mechanisms of titanium dioxide as ultraviolet-blocking additive for films and fabrics by an improved scheme. J. Appl. Polym. Sci. 2004, 92, 3201-3210. [CrossRef]

7. Völz, H.G.; Kischkewitz, J.; Woditsch, P.; Westerhaus, A.; Griebler, W.-D.; De Liedekerke, M.; Buxbaum, G.; Printzen, H.; Mansmann, M.; Räde, D.; et al. Inorganic Pigments. In Ullmann's Encyclopedia of Industrial Chemistry; Wiley-VCH Verlag GmbH \& Co. KGaA: Weinheim, Germany, 2000.

8. Gázquez, M.J.; Bolívar, J.P.; Garcia-Tenorio, R.; Vaca, F. A Review of the Production Cycle of Titanium Dioxide Pigment. Mater. Sci. Appl. 2014, 5, 441-458. [CrossRef]

9. Buxbaum, G. Industrial Inorganic Pigments; John Wiley \& Sons: Hoboken, NJ, USA, 2008.

10. Chen, X.; Mao, S.S. Titanium Dioxide Nanomaterials: Synthesis, Properties, Modifications, and Applications. Chem. Rev. 2007, 107, 2891-2959. [CrossRef] [PubMed]

11. Costa, A.; Chiarello, G.L.; Selli, E.; Guarino, M. Effects of $\mathrm{TiO}_{2}$ based photocatalytic paint on concentrations and emissions of pollutants and on animal performance in a swine weaning unit. J. Environ. Manag. 2012, 96, 86-90. [CrossRef] [PubMed]

12. Fecheyr-Lippens, D.C.; Igic, B.; D’Alba, L.; Hanley, D.; Verdes, A.; Holford, M.; Waterhouse, G.I.; Grim, T.; Hauber, M.E.; Shawkey, M.D. The cuticle modulates ultraviolet reflectance of avian eggshells. Biol. Open 2015, 4, 753-759. [CrossRef] [PubMed]

13. Kamkum, P.; Atiwongsangthong, N.; Muanghlua, R.; Vittayakorn, N. Application of chicken eggshell waste as a starting material for synthesizing calcium niobate $\left(\mathrm{Ca}_{4} \mathrm{Nb}_{2} \mathrm{O}_{9}\right)$ powder. Ceram. Int. 2015, 41 (Suppl. S1), S69-S75. [CrossRef]

14. Wei, Z.; Xu, C.; Li, B. Application of waste eggshell as low-cost solid catalyst for biodiesel production. Bioresour. Technol. 2009, 100, 2883-2885. [CrossRef] [PubMed]

15. Yoo, S.; Hsieh, J.S.; Zou, P.; Kokoszka, J. Utilization of calcium carbonate particles from eggshell waste as coating pigments for ink-jet printing paper. Bioresour. Technol. 2009, 100, 6416-6421. [CrossRef] [PubMed]

16. Fedor, G.R.; Brennan, P.J. Comparison between natural weathering and fluorescent UV exposures: UVA-340 lamp test results. ASTM Spec. Tech. Publ. 1996, 1294, 91-105.

17. Kohan, M.I. Nylon Plastics Handbook; Hanser: New York, NY, USA, 1995; Volume 378.

18. Kopitkovas, G.; Lippert, T.; David, C.; Wokaun, A.; Gobrecht, J. Surface micromachining of UV transparent materials. Thin Solid Films 2004, 453, 31-35. [CrossRef]

19. Jelle, B.P. Accelerated climate ageing of building materials, components and structures in the laboratory. J. Mater. Sci. 2012, 47, 6475-6496. [CrossRef]

20. Grossman, D.M. Correlation Questions \& Answers. 1984. Available online: http://life.q-lab.cn/documents / public/7e877944-fcfa-41e6-9a52-3de77c8a6d6d.pdf (accessed on 2 February 2016).

21. Wen, Z.; Hu, X.; Shen, D. The FTIR studies of photo-oxidative degradation of polypropylene. Chin. J. Polym. Sci. 1988, 6, 285-288.

22. R Development Core Team. R: A Language and Environment for Statistical Computing; R Foundation for Statistical Computing: Vienna, Austria, 2013; Available online: http://www.R-project.org (accessed on 17 December 2016).

23. Lahti, D.C.; Ardia, D.R.; Dudley, R.; Bronstein, J.L. Shedding Light on Bird Egg Color: Pigment as Parasol and the Dark Car Effect. Am. Nat. 2016, 187, 547-583. [CrossRef] [PubMed]

24. Thanki, P.N.; Singh, R.P. Photo-oxidative degradation of nylon 66 under accelerated weathering. Polymer 1998, 39, 6363-6367. [CrossRef]

25. Hirose, F.; Kuribayashi, K.; Suzuki, T.; Narita, Y.; Kimura, Y.; Niwano, M. UV Treatment Effect on $\mathrm{TiO}_{2}$ Electrodes in Dye-Sensitized Solar Cells with N719 Sensitizer Investigated by Infrared Absorption Spectroscopy. Electrochem. Solid-State Lett. 2008, 11, A109-A111. 
26. Zan, L.; Tian, L.; Liu, Z.; Peng, Z. A new polystyrene-- $\mathrm{TiO}_{2}$ nanocomposite film and its photocatalytic degradation. Appl. Catal. Gen. 2004, 264, 237-242. [CrossRef]

27. Chen, X.D.; Wang, Z.; Liao, Z.F.; Mai, Y.L.; Zhang, M.Q. Roles of anatase and rutile $\mathrm{TiO}_{2}$ nanoparticles in photooxidation of polyurethane. Polym. Test. 2007, 26, 202-208. [CrossRef]

28. Walton, H.V.; Cotterill, O.J.; Vandepopuliere, J.M. Composition of Shell Waste from Egg Breaking Plants. Poult. Sci. 1973, 52, 1836-1841. [CrossRef]

29. Than, M.M.; Lawanprasert, P.; Jateleela, S. Utilization of eggshell powder as excipient in fast and sustained release acetaminophen tablets. Mahidol Univ. J. Pharm. Sci. 2012, 39, 32-38.

30. Tegethoff, F.W.; Rohleder, J.; Kroker, E. Calcium Carbonate: From the Cretaceous Period into the 21st Century; Springer Science \& Business Media: Berlin, Germany, 2001.

31. Mann, S. Biomineralization: Concepts in Bioinorganic Materials Chemistry; Oxford University Press: Oxford, UK, 2001.

32. Gower, L.B. Biomimetic model systems for investigating the amorphous precursor pathway and its role in biomineralization. Chem. Rev. 2008, 108, 4551-4627. [CrossRef] [PubMed]

33. Okumura, T.; Suzuki, M.; Nagasawa, H.; Kogure, T. Microstructural control of calcite via incorporation of intracrystalline organic molecules in shells. J. Cryst. Growth 2013, 381, 114-120. [CrossRef]

34. Yousif, E.; Haddad, R. Photodegradation and photostabilization of polymers, especially polystyrene: Review. SpringerPlus 2013, 2, 398. [CrossRef] [PubMed]

35. Ricci, A.; Chrétien, M.N.; Maretti, L.; Scaiano, J.C. TiO 2 -promoted mineralization of organic sunscreens in water suspension and sodium dodecyl sulfate micelles. Photochem. Photobiol. Sci. 2003, 2, 487-492. [CrossRef]

36. Dondi, D.; Albini, A.; Serpone, N. Interactions between different solar UVB/UVA filters contained in commercial suncreams and consequent loss of UV protection. Photochem. Photobiol. Sci. 2006, 5, 835-843. [CrossRef] [PubMed]

(C) 2017 by the authors; licensee MDPI, Basel, Switzerland. This article is an open access article distributed under the terms and conditions of the Creative Commons Attribution (CC BY) license (http:/ / creativecommons.org/licenses/by/4.0/). 